\title{
OPEN Optimization of entrapment efficiency and release of clindamycin in microsponge based gel
}

\begin{abstract}
ALAA KHATTAB ${ }^{\bowtie}$ \& Abdulhakim Nattouf
The aim of the present study was to formulate clindamycin (CLN) as a microsponge based gel to release the drug in a controlled manner and reduce the side effects in the treatment of acne. Since this method requires poor water solubility of the drug to be loaded in particles, therefore, conversion of the hydrochloride salt to free base was done. By using an emulsion solvent diffusion method, we made six different formulations of microsponges containing CLN-free base by changing the proportions of polymer, emulsifier and the $\mathrm{pH}$ of the external phase. These formulations were studied for physical characterization and for drug- polymer interactions. The physical characterization showed that microsponge formulations coded by $\mathrm{C} 5, \mathrm{C} 6$ resulted in a better loading efficiency and production yield and their particle size was less than $30 \mu \mathrm{m}$. Scanning electron microscopy images showed the microsponges porous and spherical. C5, C6 microsponge formulation was prepared as gel in Carbopol and in vitro evaluated. The microsponge formulation gel $\mathrm{C} 8$ was found to be optimized. C 8 released $90.38 \%$ of drug over $12 \mathrm{~h}$ and showed viscosity $20,157 \pm 38 \mathrm{cp}, \mathrm{pH}$ of $6.3 \pm 0.09$ and drug content of $99.64 \pm 0.04 \%$. Fourier transform infrared spectroscopy and differential scanning calorimetry confirmed no significant interactions between excipients and drug.
\end{abstract}

Clindamycin (CLN) is a potent lincosamide antibiotic against susceptible anaerobic bacteria and gram-positive aerobes. It exhibits bacteriostatic action by binding to the $50 \mathrm{~s}$ subunit of bacterial ribosomes and inhibiting protein synthesis. At high concentrations, CLN may exhibit bactericidal activity ${ }^{1}$. Furthermore, CLN also has anti-inflammatory activities ${ }^{2}$. This medication is administered orally or parenterally to treat infections of the lungs, skin, blood, female reproductive organs, and internal organs. In addition, it is applied topically in the management of acne vulgaris ${ }^{1}$.

Acne vulgaris is a widespread follicular skin disorder that typically affects the Pilosebaceous unit of the face and upper part of the body and is triggered by different factors involving follicular hyperkeratosis, excess sebum production, Propionibacterium acnes hyperproliferation and inflammation. These factors produce noninflammatory or inflammatory lesions that can be serious and leave scars ${ }^{3}$. Therefore, acne may have severe psychosocial consequences resulting in social isolation, emotional problems and depression. Topical treatment is the first line therapy for acne, and CLN, as a gel or a solution, is one of the most common and efficacious topical anti acne agents. Due to anti-bacterial and anti-inflammatory properties of CLN, it targets two key factors in acne pathogenesis: P. acnes colonization and inflammation ${ }^{4}$. However, conventional topical formulations of CLN immediately release the drug upon application in excessive concentrations over a short period of time, and then they release the drug in relatively low concentrations. Thus, resulting in two critical problems, the first one is cutaneous side effects such as irritation, dryness, oiliness, itching, erythema and peeling. These side effects may be serious and represent a troublesome issue for acne patients who have been afflicted psychologically and already suffering from inflamed lesions ${ }^{5}$. The other problem is the short duration of drug action, thereby, the drug should be applied two times daily ${ }^{1}$. In addition, CLN may have unpleasant odor which cannot be masked via commercial products ${ }^{6}$. As a result, limitations of conventional topical preparations of CLN may lead to poor patient compliance and reduction in treatment efficacy. Therefore, it is prudent to develop a new technique for delivering CLN that overcomes the disadvantages of its marketed products.

Microsponge technology ideally addresses the problems discussed above due to its several attractive features. Microsponges are polymeric, porous microspheres entrapping the active ingredients inside their tiny voids. These microparticles are retained in the crannies of the skin without passing through it and gradually release proper

Faculty of Pharmacy, Damascus University, Damascus, Syria. ${ }^{\circledR}$ email: alaakhattab366@gmail.com 


\begin{tabular}{|l|l|l|l|l|l|l|}
\hline Ingredients & C1 & C2 & C3 & C4 & C5 & C6 \\
\hline CLN free base (mg) & 100 & 100 & 100 & 100 & 100 & 100 \\
\hline Ethyl cellulose (mg) & 200 & 300 & 300 & 200 & 200 & 300 \\
\hline Dichloromethane (ml) & 20 & 20 & 20 & 20 & 20 & 20 \\
\hline PVA (mg) & 200 & 200 & 300 & 300 & 200 & 300 \\
\hline Distilled water (ml) & 150 & 150 & 150 & 150 & - & - \\
\hline NaOH $(0.01 \mathrm{~N})(\mathrm{ml})$ & - & - & - & - & 150 & 150 \\
\hline
\end{tabular}

Table 1. Formulae for microsponges of CLN-free base.

concentrations of the drug at the targeted site for a prolonged period. Thus, microsponges would control the drug delivery, enhance the drug tolerability, and reduce the frequency of application while still sustaining the efficacy of the drug. In addition, they could absorb sebaceous secretions which are highly found on the skin of most acne patients without cause drying. Furthermore, they may encapsulate the drug and mask its undesirable characteristics. As a result, microsponges would improve patients' acceptance and adherence to the treatment, as well as maximize the therapeutic outcomes ${ }^{7,8}$. Based on the previous facts, we aimed in the present work to design a sustained release topical formulation of CLN by incorporating CLN into microsponges and dispersing CLN loaded microsponges into Carbopol gel as a vehicle. However, CLN is commercially available as CLN-HCl and CLN-PO4, Both of which are freely soluble in water, and it is a challenging task to incorporate them into microsponges via quasi emulsion solvent diffusion method, as high amounts of the freely soluble drug would leach into the external aqueous phase during formulation and lead to low drug entrapment ${ }^{9}$.

Thus, we attempted in this study to use CLN-free base (the slightly soluble form of the drug) instead of CLN-HCl or CLN-Po4 and change $\mathrm{pH}$ of the external aqueous phase as a dual approach in order to maintain the drug in the internal phase during the formulation and prevent its leaching into the external aqueous phase, which could, in turn, achieve maximum drug entrapment. To the best of our knowledge, this study presents the first attempt to use the dual approach mentioned above for formulating highly soluble drugs like CLN-HCl into microsponges, and the first attempt to develop sustained release microsponge based gel of CLN-free base.

\section{Materials and methods}

Materials. Clindamycin $\mathrm{HCl}$ was purchased from Sigma-Aldrich (Germany). Polyvinyl Alcohol was obtained from HiMedia labs (Mumbai). Carbopol 934 was bought from Loba chemie (India). Ethyl cellulose was obtained from Sigma-Aldrich (Germany). Dichloromethane, Ethanol, Sodium hydroxide and HPLC solvents were of analytical grade and purchased from Merck (Germany).

Methods. CLN-HCl conversion from hydrochloride salt to base. CLN-HCl was converted to the corresponding free base by treatment with $\mathrm{NaOH}$ as previously described ${ }^{10}$. The detailed methods were as follows. A CLN-HCl solution was prepared by dissolving $57.1 \mathrm{~g}$ of CLN-HCl in $170 \mathrm{~mL}$ of deionized water in a $500 \mathrm{~mL}$ beaker. About $120 \mathrm{~mL}$ of $1.0 \mathrm{~N} \mathrm{NaOH}$ was slowly added to the solution. The solution became cloudy and large white sticky ball-like lumps formed at the bottom of the beaker. The solution mixture in the beaker from the preceding step was stirred by glass rod until the ball-like lumps were manually deaggregated. After deaggregation, the ball-like lumps became small white solid species and were precipitated in the solution, which indicated CLN-free base was formed. Finally, the precipitate was dried by vacuum drier and stored before use.

Preparation of CLN-free base microsponges. The microsponges enclosing CLN-free base were fabricated by quasi-emulsion solvent diffusion method. The method consisted of preparing two phases: the inner phase and the outer phase. The inner phase comprises ethylcellulose (as mentioned in Table 1) dissolved in $20 \mathrm{~mL}$ of DCM. Once a clear solution was obtained, the CLN-free base was added and dissolved through ultrasonication at $25^{\circ} \mathrm{C}$ for $30 \mathrm{~min}$ to obtain a homogenous clear solution. Then, this mixture was added dropwise into an aqueous solution of PVA (outer phase) with a stirring rate $1200 \mathrm{rpm}$ for $3 \mathrm{~h}$. Subsequently, microsponges were formed due to the DCM removal from the system by evaporation. The prepared microsponges were then filtered, washed with distilled water, and subjected to drying at $40{ }^{\circ} \mathrm{C}$ for $24 \mathrm{~h}$ in a hot air oven ${ }^{11}$. As shown in Table 1 , various formulation batches were prepared.

Evaluation of microsponge.

1. Production yield and entrapment efficacy

The entrapment and yield of the microsponge system was calculated using the following equations ${ }^{12}$ :

$$
\text { Production yield } \%=\frac{\text { weight of the dried microsponges }}{\text { sum of the initial dry weight of starting materials }} \times 100
$$




\begin{tabular}{|l|l|l|}
\hline Ingredients & C7 & C8 \\
\hline Microsponges $(\mathrm{mg})$ & C5 formula equivalent to 1 g of drug & C6 formula equivalent to 1 g of drug \\
\hline Carbopol 934 $(\mathrm{g})$ & 0.3 & 0.3 \\
\hline Glycerine $(\mathrm{g})$ & 5 & 5 \\
\hline Triethanolamine & q.s & q.s \\
\hline Methyl paraben $(\mathrm{g})$ & 0.18 & 0.18 \\
\hline Propyl paraben $(\mathrm{g})$ & 0.02 & 0.02 \\
\hline EDTA $(\mathrm{g})$ & 0.05 & 0.05 \\
\hline Distilled water $(\mathrm{g})$ & q.s.100 & q.s.100 \\
\hline
\end{tabular}

Table 2. Formulae for microsponge loaded gels of CLN-free base.

$$
\text { Entrapment efficacy } \%=\frac{\text { actual drug content }}{\text { theoretical drug content }} \times 100
$$

2. Particle size evaluation

The average particle size of CLN loaded microsponges was determined with an optical microscope using a calibrated ocular and stage micrometer.

3. Scanning electron microscope (SEM)

The microsponge formulation C6 was visualized by SEM to assess the morphology and surface characteristics of the microsponges. (SEM, TESCAN, VEGA, Czech republic) ${ }^{13}$

4. Preparation of CLN-free base microsponge gel

Gel of CLN-free base is prepared by using the following formula given in Table 2. A clear dispersion of Carbopol 934 was prepared in mixture of water and glycerine using moderate agitation. Parabens and Edetate disodium were dissolved in water and added to the previous mixture. Triethanolamine was used to neutralize the obtained viscous solution with slow agitation. At this stage, $\mathrm{CLN}$-free base microsponges (equivalent to $1 \% \mathrm{w} / \mathrm{w}$ of CLN-free base) were incorporated to obtain homogenous CLN microsponge-loaded gels.

Gel evaluation.

1. Appearance

The formulated gels were examined visually for their color, appearance, and consistency.

2. Determination of $\mathrm{pH}$

The $\mathrm{pH}$ of the formulation was determined by using a digital $\mathrm{pH}$ meter (HANNA 211).

3. Determination of viscosity

The viscosity of the formulation was studied by a digital viscometer (Rotary viscometer STS-2011) using spindle R7 at $25 \pm 10^{\circ} \mathrm{C}$.

4. Determination of drug content

One gram of formulation was diluted with $100 \mathrm{~mL}$ of ethanol $95 \%$ with proper mixing. The solution was filtered and was analysed for drug content by HPLC method with proper dilution of the sample.

5. In vitro drug release studies

In vitro release studies were performed using cellulose nitrate membrane. For this experiment, a vertical Franz diffusion cell with a surface area of $2.54 \mathrm{~cm}^{2}$ and a reservoir capacity of $9.5 \mathrm{~mL}$ was used. The membrane was placed between the two halves of the diffusion cell. The receptor compartment contained a mixture of water and ethanol $(50: 50, \mathrm{v} / \mathrm{v})$, and its temperature was maintained at $32 \pm 0.1{ }^{\circ} \mathrm{C}$ and stirred continuously using a magnetic stirrer. Each formulation weighing $0.5 \mathrm{~g}$ of microsponge based gel was placed on the donor side. A total of $2 \mathrm{~mL}$ of the sample was withdrawn from the receptor compartment at definite time intervals and replaced with an equal volume of fresh receptor fluid. The aliquots were suitably diluted with the receptor medium and analysed by HPLC method ${ }^{14-16}$.

6. In vitro drug release kinetics

To investigate the release mechanism of CLN-free base from the microsponge loaded gels, the release data was analysed using zero order, first order, Higuchi, Hixson-Crowell, and Korsmeyer-Peppas.

7. Stability study

Optimized batches of CLN microsponge gels were monitored for up to 6 months at $40 \pm 2^{\circ} / 75 \pm 5 \%$ RH as per ICH guidelines ${ }^{17}$. At the interval of $1,2,3,4,5$, and 6 months, samples were withdrawn and analysed to determine changes in appearance, $\mathrm{pH}$, viscosity and drug content, and drug release ${ }^{14}$.

Compatibility study.

1. Differential scanning colorimetry (DSC) 


\begin{tabular}{|l|l|l|}
\hline Formula & EE $(\%) \pm$ SD & PY $\% \pm$ SD \\
\hline C1 & $70.02 \pm 0.23$ & $51.93 \pm 0.29$ \\
\hline C2 & $75.36 \pm 0.31$ & $62.42 \pm 0.18$ \\
\hline C3 & $73.72 \pm 0.07$ & $58.37 \pm 0.27$ \\
\hline C4 & $63.92 \pm 0.62$ & $30.64 \pm 0.38$ \\
\hline C5 & $93.15 \pm 0.01$ & $78.68 \pm 0.39$ \\
\hline C6 & $99.61 \pm 0.04$ & $85.19 \pm 0.01$ \\
\hline
\end{tabular}

Table 3. Results of CLN-free base microsponge EE\% and PY\%.

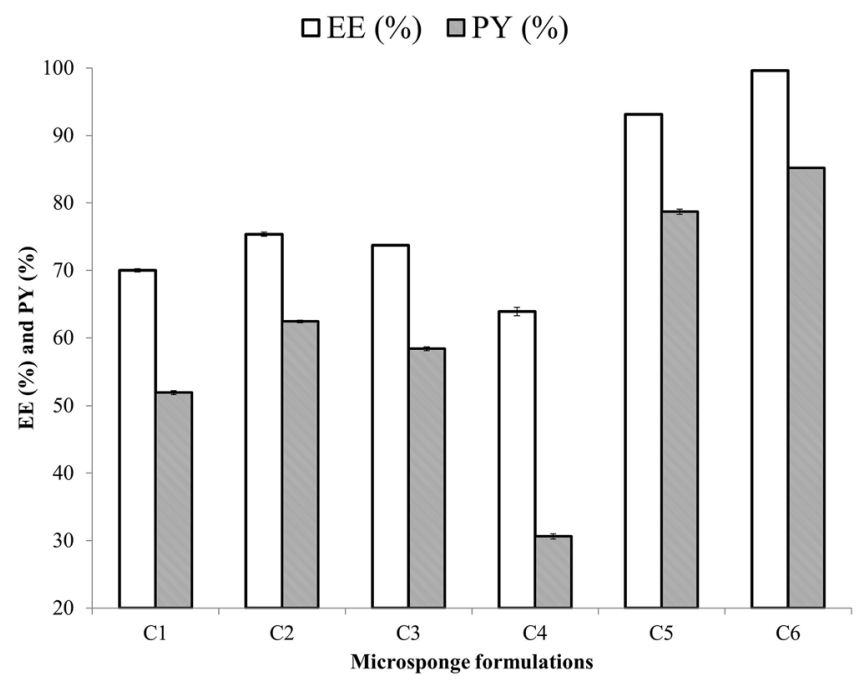

Figure 1. Graph Showing EE (\%) and PY (\%). Data are expressed as mean \pm SD $(n=3)$.

The DSC for drug and formulation C6 was studied (DSC131, SETARAM, France). Accurately weighed samples were transferred to aluminium pans and sealed. Samples were run at a heating rate of $10{ }^{\circ} \mathrm{C} / \mathrm{min}$ over a temperature range $25-450^{\circ} \mathrm{C}$ in an atmosphere of nitrogen ${ }^{18}$.

2. Fourier transformer infrared spectroscopy (FTIR)

To ascertain compatibility, FTIR spectra of CLN-free base and other excipients were recorded in $\mathrm{KBr}$ disc. (Bruker IR, Germany) ${ }^{19}$.

Statistical analysis. The results represented are the mean of three determinations. Data was subjected to Student's $t$-test. $P<0.05$ was considered indicative of significance, using Microsoft Excel 2010.

\section{Results and discussion}

Evaluation of the formulated microsponge production yield\% (PY\%) and entrapment efficacy\% (EE\%). The production yields and entrapment efficacy of CLN microsponge formulations are given in Table 3 and Fig. 1. All formulations revealed high EE\% and PY\%, which could be attributed to the porous structure of the microsponge formulations. Table 3 showed that the production yield and entrapment efficacy of microsponges significantly increased by increasing the amount of EC for a constant level of PVA, whereas increasing PVA concentration for a given value of EC produced microsponges with low EE\% and PY\%. These results can be explained by the high level of EC delays the diffusion of the organic phase to the aqueous phase due to higher viscosity of the organic phase. This provided more time for droplet formation and improved the yield and entrapment efficacy of the microsponges ${ }^{20}$. On the other hand, PVA is a nonionic emulsifier that forms hydrophobic regions, which dissolve some of the drug and polymer, thereby resulting in lower EE\% and PY\% ${ }^{21}$. To study the effect of $\mathrm{pH}$ on the entrapment efficacy and production yield of the prepared CLN-free base microsponges, distilled water at pH 5.8 and $0.01 \mathrm{~N} \mathrm{NaOH}$ solution at pH 11 were used as an external phase. Microsponge formulations coded by $\mathrm{C} 5$, C6 were prepared as microsponge formulations coded by $\mathrm{C} 1, \mathrm{C} 3$ respectively, except that distilled water was replaced with $0.01 \mathrm{~N} \mathrm{NaOH}$ solution. Results listed in Table 3 showed that increasing the $\mathrm{pH}$ of the external phase from 5.8 to 11 led to a significant increase in drug entrapment and yield. For example, The entrapment efficacy and production yield of CLN-free base were $73.72 \pm 0.07 \%$ and $58.37 \pm 0.27 \%$ respectively, with using distilled water at $\mathrm{pH} 5.8$ as the outer phase, whereas they dramatically increased up to $99.61 \pm 0.04 \%$ and $85.19 \pm 0.01 \%$ respectively, by using $0.01 \mathrm{~N} \mathrm{NaOH}$ solution at $\mathrm{pH} 11$ as the external phase. This increased drug entrapment and yield is most likely due to a change in the degree of CLN-free base ionization. Namely, in $0.01 \mathrm{~N} \mathrm{NaOH}$ solution at $\mathrm{pH} 11, \mathrm{CLN}$-free base was less ionized and therefore less soluble than in 


\begin{tabular}{|l|l|}
\hline Formula & Particle size $(\boldsymbol{\mu m}) \pm$ SD \\
\hline C1 & $21.92 \pm 0.12$ \\
\hline C2 & $33.73 \pm 0.91$ \\
\hline C3 & $25.17 \pm 1.58$ \\
\hline C4 & $15.26 \pm 0.07$ \\
\hline C5 & $23.47 \pm 1.22$ \\
\hline C6 & $26.49 \pm 1.03$ \\
\hline
\end{tabular}

Table 4. Results of CLN-free base microsponge particle size.

distilled water at $\mathrm{pH}$ 5.8. This may have therefore reduced partitioning of drug from the internal phase into the external aqueous and thus enhanced drug entrapment and yield into microsponges ${ }^{22}$.

Particle size. The particle sizes of CLN microsponge formulations are tabulated in Table 4. The particle size of CLN microsponges increased upon the increase in EC concentration. This could be explained by the fact that, at higher drug-polymer ratio, the available polymer was higher, thus increasing the polymer wall thickness, which led to increased size of the microsponges ${ }^{23}$. On the other hand, the particle size of CLN microsponges decreased upon the increase in PVA concentration. This was most probably due to the decrease in surface tension of the continuous phase by increasing the surfactant concentration, which results in smaller emulsion droplets and consequently smaller particle size ${ }^{24}$.

Selection of optimized formulations. Microsponge formulations with particle size less than $30 \mu \mathrm{m}$ (to avoid any gritty feeling) and maximum EE\% and PY\% (C5, C6) were considered as optimized formulations. Therefore, they were incorporated into gel base and further evaluated.

Scanning electron microscope (SEM). The representative SEM photographs of the microsponge formulations (C5, C6) are shown in Fig. 2. SEM images showed the microsponges were spherical and devoid of aggregation. Therefore, they would easily disperse into the gel formulation. In addition, the drug crystals were not seen on the surface of the microsponges. This indicates the dispersion of the drug inside the polymeric matrix which is interpreted in DSC analysis.

Appearance and physical parameters of gels. The formulated gels were clear and transparent and showed the viscosity of $20,157 \pm 38-21,911 \pm 29 \mathrm{cps}, \mathrm{pH}$ of $6.3 \pm 0.09-6.5 \pm 0.1$, and drug content of $99.64 \pm 0.04$ to $100.13 \pm 0.29 \%$ respectively. $\mathrm{pH}$ values of all formulations are suitable for application to skin. The drug content of the formulations showed that the drug was uniformly distributed in the formulations. This is given in Table 5.

In vitro drug release studies. The in vitro performance of CLN-free base microsponge gels showed prolonged release of CLN. The results of the in vitro drug release studies of formulations C7 and C8 are shown in Fig. 3. The results of C8 formulation prepared with $300 \mathrm{mg}$ EC showed a release of $90.38 \%$ in $12 \mathrm{~h}$, while C7 formulation prepared with $200 \mathrm{mg}$ EC showed a release of $92.39 \%$ in $9 \mathrm{~h}$. Thus, the extent of drug release depended on EC levels. This could be explained by the significant increase in particle size of microsponges by increasing polymer concentration, which leads to a longer diffusion path, and consequently a slower release rate ${ }^{25}$. In addition, no initial burst release was seen during the first hours of drug release from both gel formulations. The reason behind that could be the absence of non-encapsulated CLN on the surface of the microsponges ${ }^{19}$. This finding is in agreement with SEM and DSC studies results. Data obtained from in vitro release studies were utilized for release kinetics, and the results of the in vitro drug release kinetics were shown in Table 6 . The in vitro drug release of the formulations C7 and C8 were best explained by Higuchi kinetic model as the plots showed linearity $\mathrm{R}^{2}=0.983$ and $\mathrm{R}^{2}=0.991$, respectively, which are shown in Table 6 . In the two formulations, $\mathrm{n}$ was found to be more than 0.5 , indicating the diffusion was Anomalous diffusion (Non-fickian diffusion) ${ }^{26}$.

Stability study. The results of the stability study of formulation C8 displayed no considerable changes in the physical appearance, $\mathrm{pH}$, and drug content. Moreover, there were no significant changes in percent drug release. After comparing the drug release profiles of formulation C8 before and after 6 months stability study, the similarity factor ( $f 2$ ) was calculated, which was found to be $f 2=83.29(>50)$, which indicates good stability of the formulation. Therefore, the formulation C8 was established as stable over the period of 6 months ${ }^{27}$. Results were shown in Table 7.

Compatibility study. Differential scanning colorimetry (DSC). To investigate the thermal behaviour of CLN-free base in the formulated microsponge, DSC study was conducted and the thermograms of CLN-free base, and microsponge formulation C6 are illustrated in Fig. 4a,b respectively. DSC thermogram of pure drug showed a sharp endothermic peak at $70.21^{\circ} \mathrm{C}$, indicating that drug crystals had melted ${ }^{10}$. On the other hand, the thermogram of CLN-free base microsponge formulation C6 in Fig. 4b exhibited a detectable loss of the melting endothermic peak of pure CLN-free base. This clearly indicated that the drug was dispersed homoge- 


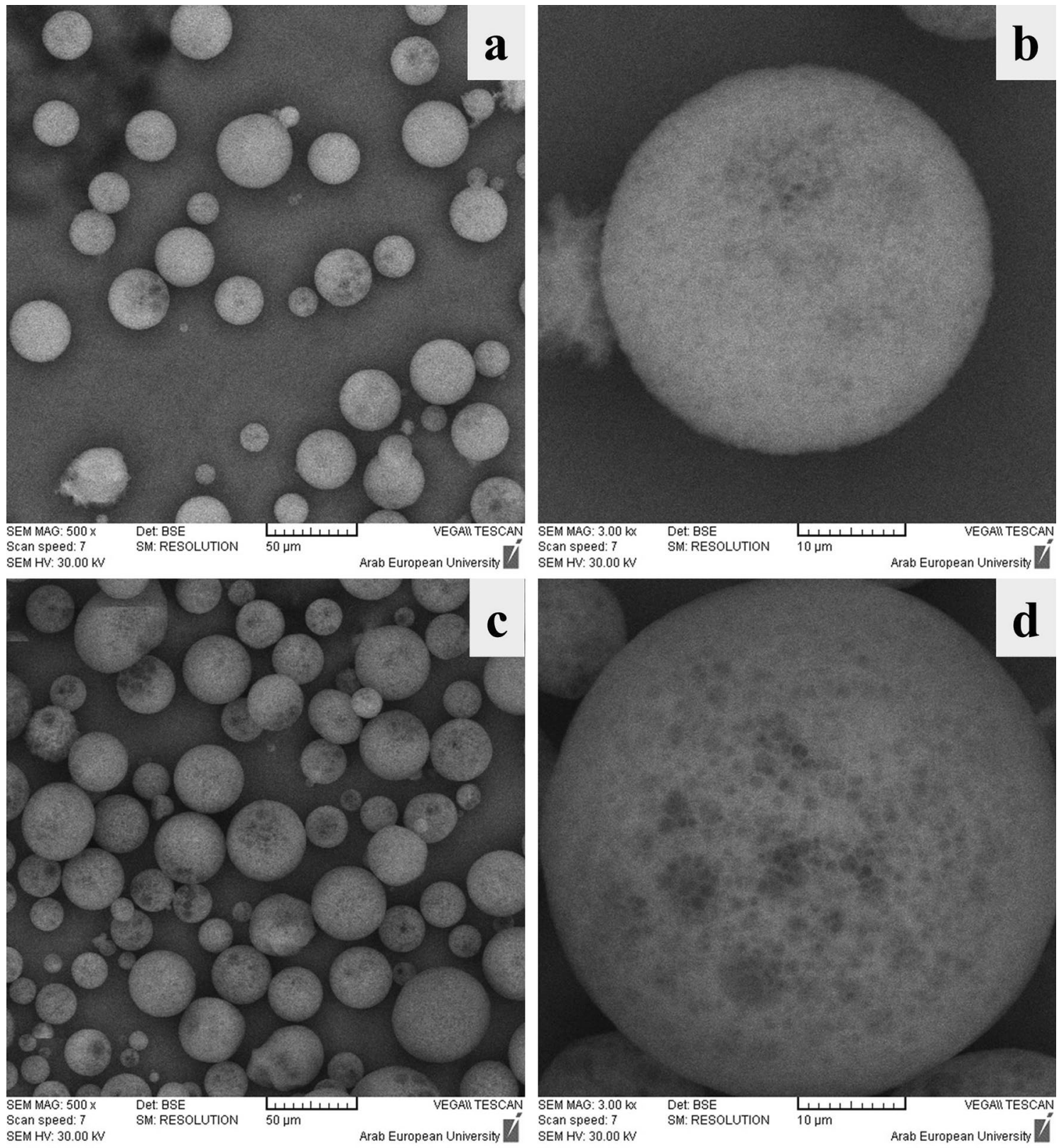

Figure 2. SEM images of (a) C5 formulation, 500x, (b) C5 formulation, 3000x, (c) C6 formulation, 500x, (d) C6 formulation, 3000x.

\begin{tabular}{|l|l|l|l|}
\hline Formula & $\mathbf{p H} \pm \mathbf{S D}$ & Viscosity $(\mathbf{c p s})$ at $25^{\circ} \mathbf{C}$ & Drug contnt $(\%) \pm \mathrm{SD}$ \\
\hline $\mathrm{C} 7$ & $6.5 \pm 0.1$ & $21,911 \pm 29$ & $100.13 \pm 0.29$ \\
\hline $\mathrm{C} 8$ & $6.3 \pm 0.09$ & $20,157 \pm 38$ & $99.64 \pm 0.04$ \\
\hline
\end{tabular}

Table 5. Results of appearance and physical parameters of CLN-free base gels.

neously throughout the microsponges and these microsponges had an amorphous structure as all cross-linked polymers ${ }^{28,29}$.

Fourier transform infrared spectroscopy FTIR. The IR spectra of CLN-free base pure powder and microsponge formulation C6 are as shown in Fig. 5a,b, respectively. CLN-free base spectrum shows peaks at the following locations: at $3686.52 \mathrm{~cm}^{-1}$ due to $\mathrm{O}-\mathrm{H}$ stretching in the galactose sugar group; at $2916.38 \mathrm{~cm}^{-1}$ due to $\mathrm{C}-\mathrm{H}$ stretching of C4-alkyl group; at $1665.63 \mathrm{~cm}^{-1}$ and $1509.32 \mathrm{~cm}^{-1}$ related to $\mathrm{N}-\mathrm{C}=\mathrm{O}$ stretching of amid carbonyl group; at $1080.19 \mathrm{~cm}^{-1}$ corresponds to $\mathrm{C}-\mathrm{O}$ cyclic ether stretching in the galactose sugar group; at $1050.44 \mathrm{~cm}^{-1}$ 


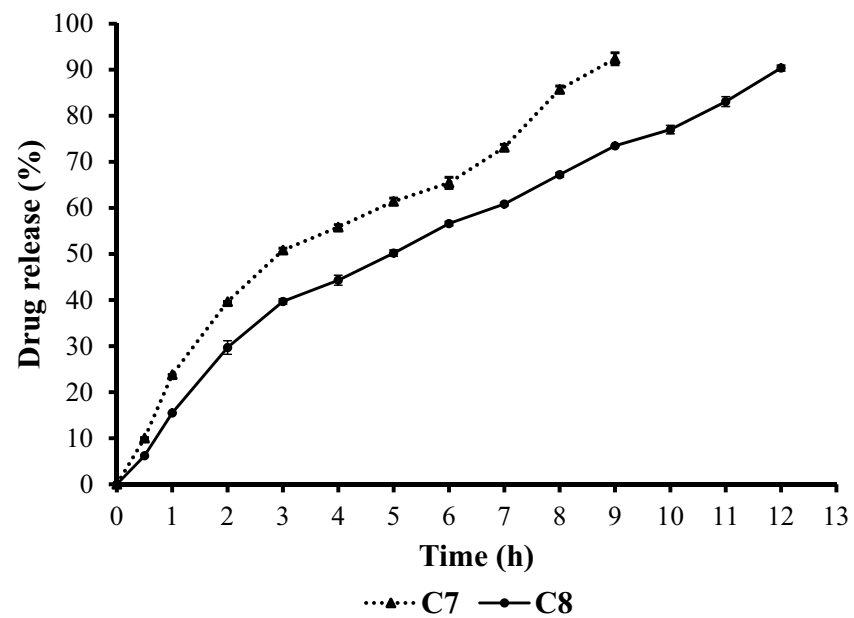

Figure 3. Percentage drug release of CLN-free base from C7 and C8 formulations against time (h). Data are expressed as mean $\pm S D(n=3)$.

\begin{tabular}{|c|c|c|c|c|c|c|}
\hline \multirow[b]{2}{*}{ Formula } & \multirow{2}{*}{$\begin{array}{l}\text { Zero } \\
\mathbf{R}^{2}\end{array}$} & \multirow{2}{*}{$\begin{array}{l}\text { First } \\
\mathbf{R}^{2}\end{array}$} & \multirow{2}{*}{$\begin{array}{l}\text { Highochi } \\
\mathrm{R}^{2}\end{array}$} & \multicolumn{2}{|c|}{ Peppas } & \multirow{2}{*}{$\begin{array}{l}\text { Hicxon } \\
\mathbf{R}^{2}\end{array}$} \\
\hline & & & & $\mathbf{R}^{2}$ & $\mathbf{n}$ & \\
\hline C7 & 0.955 & 0.906 & 0.983 & 0.965 & 0.7 & 0.846 \\
\hline $\mathrm{C} 8$ & 0.964 & 0.942 & 0.991 & 0.955 & 0.7 & 0.831 \\
\hline
\end{tabular}

Table 6. Results of the in vitro drug release kinetics of $\mathrm{C} 7$ and $\mathrm{C} 8$ formulations.

\begin{tabular}{|l|l|l|l|l|}
\hline Time (months) & Physical appearance & $\mathbf{p H} \pm \mathbf{S D}$ & Drug content $(\%) \pm$ SD & $\mathbf{C D R}(\%) \pm$ SD \\
\hline 0 & - & $6.3 \pm 0.09$ & $99.64 \pm 0.04$ & $90.38 \pm 0.02$ \\
\hline 1 & No change & $6.4 \pm 0.01$ & $98.28 \pm 0.03$ & $89.36 \pm 0.04$ \\
\hline 2 & No change & $6.3 \pm 0.04$ & $99.45 \pm 0.02$ & $88.25 \pm 0.03$ \\
\hline 3 & No change & $6.3 \pm 0.02$ & $99.26 \pm 0.02$ & $88.18 \pm 0.08$ \\
\hline 4 & No change & $6.5 \pm 0.07$ & $98.48 \pm 0.03$ & $89.7 \pm 0.04$ \\
\hline 5 & No change & $6.5 \pm 0.02$ & $97.84 \pm 0.03$ & $89.39 \pm 0.07$ \\
\hline 6 & No change & $6.4 \pm 0.03$ & $97.23 \pm 0.03$ & $90.32 \pm 0.03$ \\
\hline
\end{tabular}

Table 7. Results of stability study of C8 formulation.

due to C-C stretching of pyrrolidine group ${ }^{30,31}$. The IR spectrum of microsponge formulation C6 is totally different from CLN-free base powder. The characteristic bands of CLN-free base either have disappeared or reduced in intensity, which might be due to the restriction inside the microsponge matrix. In the infrared spectra of CLNfree base microsponge formulation C6, no additional peak was observed, which emphasized the absence of any possible interaction between CLN-free base and other excipients ${ }^{32}$.

\section{Conclusions}

The aim of this study was to develop a sustained release microsponge based gel of CLN-HCl as a model for a highly water-soluble drug with high entrapment efficiency of the drug inside microsponges and acceptable other physicochemical properties. Initially, $\mathrm{CLN}-\mathrm{HCl}$ was converted to CLN-free base. Then four formulations of CLNfree base loaded microsponges, C1, C2, C3 and C4 were prepared by quasi emulsion solvent diffusion method using two levels of EC (200 mg, $300 \mathrm{mg}$ ) and two levels of PVA (200 mg, $300 \mathrm{mg}$ ) and evaluated for their yield, entrapment efficacy and size. In an attempt to obtain microsponge formulations with higher yield and entrapment efficacy, $\mathrm{C} 5$ and $\mathrm{C} 6$ formulations were prepared by changing $\mathrm{pH}$ of the external aqueous phase from 5.8 to 11 via using $0.01 \mathrm{~N} \mathrm{NaOH}$ solution instead of distilled water. C5 and C6 formulations had significantly high yield and entrapment efficacy as well as they had a particle size less than $30 \mu \mathrm{m}$ suitable for dermal application. In addition, SEM images of these formulations revealed that microsponges were spherical, devoid of aggregation, and had a smooth surface without any free drug content. Further, $\mathrm{C} 7$ and C8 formulations were prepared by incorporating microsponge formulation C5 and C6 into Carbopol gel respectively and evaluated for appearance, viscosity, $\mathrm{pH}$, drug content, In vitro drug release, In vitro drug release kinetics. Each of C7 and C8 formulations was clear and 


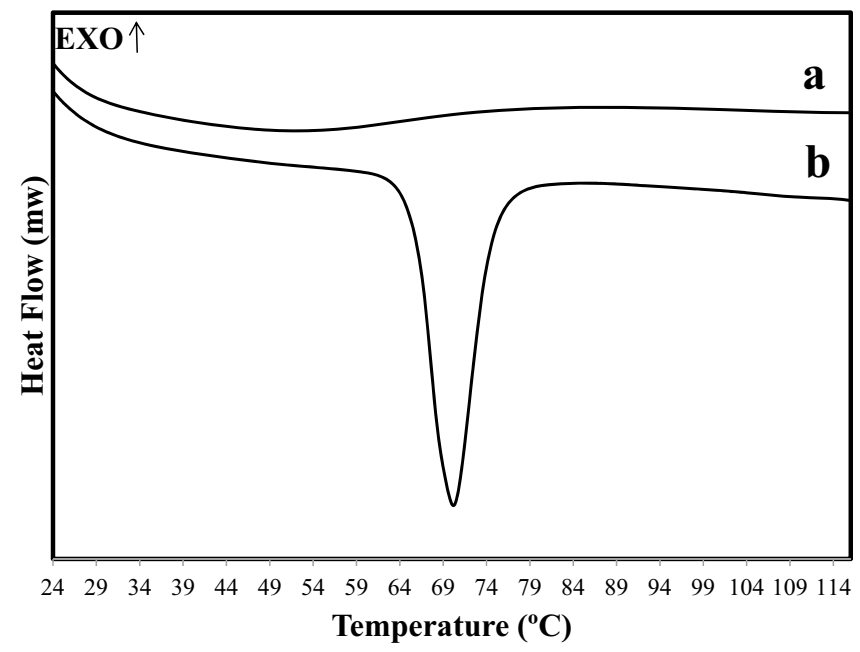

Figure 4. DSC thermograms of (a) pure CLN-free base, (b) C6 formulation.

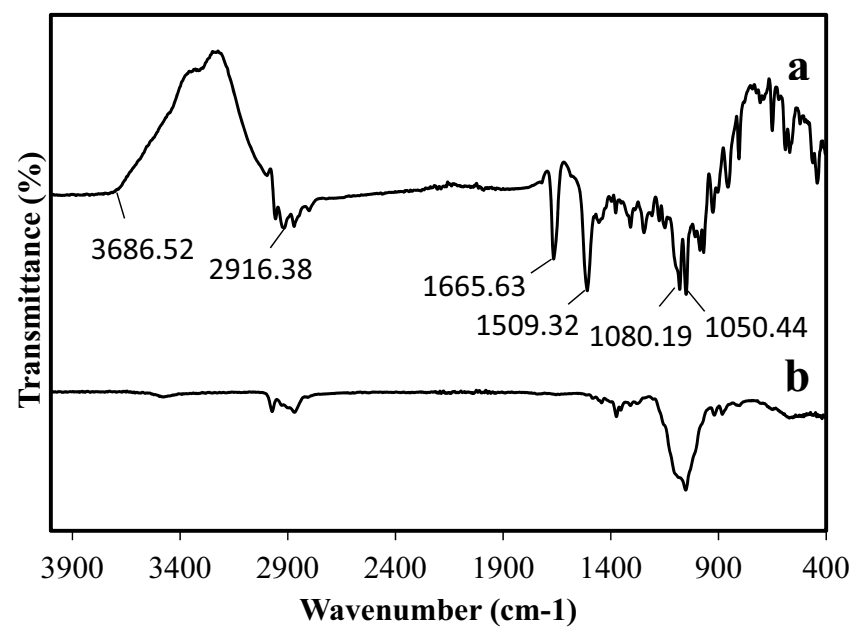

Figure 5. FTIR spectra of (a) pure CLN-free base, (b) C6 formulation.

transparent and had acceptable viscosity, $\mathrm{pH}$ and drug content. In vitro drug release study showed that both of C7 and C8 formulations extended the drug release for a longer time without any burst release effect. However, C8 formulation exhibited a little superiority over C7 formulation since it released the drug up to $12 \mathrm{~h}$. After the stability testing for a period of six months, C8 formulation was established as stable. In addition, FTIR and DSC studies indicated drug-polymer compatibility and amorphous nature of the microsponges structure. Eventually, microsponge gel formulations of CLN-free base were successfully developed with notable high entrapment efficiency and precise controlled release. Therefore, these formulations can be considered as promising delivery systems for CLN, by reducing side effects, decreasing frequency of application, enhancing aesthetic properties and improving patient compliance. On the other hand, this study opens the door for further consideration of the potential incorporation of CLN-free base loaded microsponges into other vehicles such as tablets or powders for systemically administration in order to get several benefits (e.g. masking the extremely bitter taste of CLN or decreasing its frequent administration). In addition, the above approaches, of converting CLN-HCl to CLN-free base and altering the aqueous phase $\mathrm{pH}$, provide future insights for developing sustained release microsponges of similar water soluble-drugs.

\section{Data availability}

Correspondence and requests for materials should be addressed to A.K.

Received: 5 August 2021; Accepted: 23 November 2021

Published online: 02 December 2021 


\section{References}

1. Brayfield, A. Martindale the complete drug reference, 38th edition, in 1696,1695,325,269-272,1724 (Pharmaceutical Press, 2014).

2. Luchian, I., Goriuc, A., Martu, M. A. \& Covasa, M. Clindamycin as an alternative option in optimizing periodontal therapy. Antibiotics 10, 1-12 (2021).

3. Vary, J. C. Selected disorders of skin appendages-acne, alopecia, hyperhidrosis. Med. Clin. N. Am. 99, 1195-1211 (2015).

4. Barnes, L. E., Levender, M. M., Fleischer, A. B. \& Feldman, S. R. Quality of life measures for acne patients. Dermatol. Clin. 30, 293-300 (2012).

5. Abdellatif, A. A. H. \& Tawfeek, H. M. Transfersomal nanoparticles for enhanced transdermal delivery of clindamycin. AAPS PharmSciTech 17, 1067-1074 (2016).

6. Daihom, B. et al. Development and physicochemical characterization of clindamycin resinate for taste masking in pediatrics. Drug Dev. Ind. Pharm. 42, 1600-1608 (2016).

7. Salah, S., Awad, G. E. A. \& Makhlouf, A. I. A. Improved vaginal retention and enhanced antifungal activity of miconazole microsponges gel: Formulation development and in vivo therapeutic efficacy in rats. Eur. J. Pharm. Sci. 114, 255-266 (2018).

8. Singhvi, G., Manchanda, P., Hans, N., Dubey, S. K. \& Gupta, G. Microsponge: an emerging drug delivery strategy. Drug Dev. Res. 80, 200-208 (2019).

9. Barakh Ali, S. F. et al. Application of salt engineering to reduce/mask bitter taste of clindamycin. Drug Dev. Ind. Pharm. 45, 1871-1878 (2019).

10. Patent application publication. crystaline clindamycin free base. 2003: Pub.No: CA2458644A1.

11. Jadhav, N. et al. Microsponge delivery system: an updated review, current status and future prospects. J. Sci. Innov. Res. 2, 1097-1110 (2013).

12. Shah, D. K. \& Agrawal, A. Formulation and evaluation of polymeric microsponges of ketoconazole for topical delivery. World J. Pharm. Pharm. Sci. 5, 939-962 (2016).

13. Rajurkar, V. G. et al. Topical anti-inflammatory gels of naproxen entrapped in eudragit based microsponge delivery system. J. $A d v$. Chem. Eng. 5, 1-6 (2015).

14. Mahaparale, P. R., Ikam, S. A. N. \& Chavan, M. S. Development and evaluation of terbinafine hydrochloride polymeric microsponges for topical drug delivery. Indian J. Pharm. Sci. 80, 1086-1092 (2018).

15. Ramanauskiene, K., Inkeniene, A. M., Puidokaite, E. \& Grigonis, A. Quality analysis of semisolid formulations with the liquid extract of elderflower (Sambucus nigra L.). Acta Pol. Pharm. Drug Res. 76, 1061-1071 (2019).

16. Raminelli, A. C. P., Romero, V., Semreen, M. H. \& Leonardi, G. R. Nanotechnological advances for cutaneous release of tretinoin: an approach to minimize side effects and improve therapeutic efficacy. Curr. Med. Chem. 25, 3703-3718 (2018).

17. ICH Guidelines Q1A (R2). Stability testing of new drug substaces and products (2003).

18. Deshmukh, K., Tanwar, Y. S., Sharma, S., Shende, P. \& Cavalli, R. Functionalized nanosponges for controlled antibacterial and antihypocalcemic actions. Biomed. Pharmacother. 84, 485-494 (2016).

19. Kumari, A., Jain, A., Hurkat, P., Tiwari, A. \& Jain, S. K. Eudragit S100 coated microsponges for Colon targeting of prednisolone. Drug Dev. Ind. Pharm. 44, 902-913 (2018).

20. Maiti, S., Kaity, S., Ray, S. \& Sa, B. Development and evaluation of xanthan gum-facilitated ethyl cellulose microsponges for controlled percutaneous delivery of diclofenac sodium. Acta Pharm. 61, 257-270 (2011).

21. Kalkotwar, R. S. Ethyl cellulose based microsponge delivery system for anti-fungal vaginal gels of tioconazole. J. Drug Deliv. Ther. 3, 14-20 (2013).

22. Jones, D. S. \& Pearce, K. J. An investigation of the effects of some process variables on the microencapsulation of propranolol hydrochloride by the solvent evaporation method. Int. J. Pharm. 118, 199-205 (1995).

23. Tripathi, P. K., Gorain, B., Choudhury, H., Srivastava, A. \& Kesharwani, P. Dendrimer entrapped microsponge gel of dithranol for effective topical treatment. Heliyon 5, e01343 (2019).

24. Obiedallah, M. M., Abdel-Mageed, A. M. \& Elfaham, T. H. Ocular administration of acetazolamide microsponges in situ gel formulations. Saudi Pharm. J. 26, 909-920 (2018).

25. Osmani, R. A. M. et al. Microsponges based novel drug delivery system for augmented arthritis therapy. Saudi Pharm. J. 23, 562-572 (2015).

26. Dash, S., Murthy, P. N., Nath, L. \& Chowdhury, P. Kinetic modeling on drug release from controlled drug delivery systems. Acta Pol. Pharm. Drug Res. 67, 217-223 (2010).

27. Galatage, S. T. \& Killedar, S. G. Floating microsponges as gastro retentive drug delivery system containing lafutidine to treat gastric ulcer. Acta Sci. Pharm. Sci. 3, 2-12 (2021).

28. Alhammid, S. N. A. Enhancement of the solubility and the dissolution rate of candesartan cilexetil using microsponge technology. Asian J. Pharm. Clin. Res. 11, 385-390 (2018).

29. Mihailiasa, M. et al. Preparation of functionalized cotton fabrics by means of melatonin loaded $\beta$-cyclodextrin nanosponges. Carbohydr. Polym. 142, 24-30 (2016).

30. Mohamed, A. I., Abd-Motagaly, A. M. E., Ahmed, O. A. A., Amin, S. \& Ali, A. I. M. Investigation of drug-polymer compatibility using chemometric-assisted UV-spectrophotometry. Pharmaceutics 9, 7 (2017).

31. Sangnim, T. et al. Design and characterization of clindamycin-loaded nanofiber patches composed of polyvinyl alcohol and tamarind seed gum and fabricated by electrohydrodynamic atomization. Asian J. Pharm. Sci. 13, 450-458 (2018).

32. Patel, M. R., Patel, R. B., Parikh, J. R. \& Patel, B. G. Formulation consideration and skin retention study of microemulsion containing tazarotene for targeted therapy of acne. J. Pharm. Investig. 46, 55-66 (2016).

\section{Author contributions}

All authors have contributed to the work and reviewed the manuscript. Specifically, A.K. conducted the experiments, analysed the results and wrote the main manuscript text and A.N. supervised the project and the interpretation of the results.

\section{Competing interests}

The authors declare no competing interests.

\section{Additional information}

Correspondence and requests for materials should be addressed to A.K.

Reprints and permissions information is available at www.nature.com/reprints.

Publisher's note Springer Nature remains neutral with regard to jurisdictional claims in published maps and institutional affiliations. 
(c) (i) Open Access This article is licensed under a Creative Commons Attribution 4.0 International cc) License, which permits use, sharing, adaptation, distribution and reproduction in any medium or format, as long as you give appropriate credit to the original author(s) and the source, provide a link to the Creative Commons licence, and indicate if changes were made. The images or other third party material in this article are included in the article's Creative Commons licence, unless indicated otherwise in a credit line to the material. If material is not included in the article's Creative Commons licence and your intended use is not permitted by statutory regulation or exceeds the permitted use, you will need to obtain permission directly from the copyright holder. To view a copy of this licence, visit http://creativecommons.org/licenses/by/4.0/.

(C) The Author(s) 2021 